Research Article

\title{
Association of lymphocytic thyroiditis and papillary thyroid carcinoma: a retrospective study done at a tertiary care centre in Kerala, India
}

\author{
Manoj Gopal V. ${ }^{1}$, Nibi Hassan ${ }^{1}$, Anju Susanna Thomas ${ }^{2}$, P. T. Thomas ${ }^{1}$ \\ ${ }^{1}$ Department of General Surgery, Pushpagiri Institute of Medical Sciences and Research Centre, Tiruvalla, Kerala \\ 689101, India \\ ${ }^{2}$ Department of Pathology, Pushpagiri Institute of Medical Sciences and Research Centre, Tiruvalla, Kerala 689101, \\ India \\ Received: 23 January 2016 \\ Accepted: 10 February 2016 \\ *Correspondence: \\ Dr. Nibi Hassan, \\ E-mail: pushpagiriceu@pushpagiri.in \\ Copyright: ( ) the author(s), publisher and licensee Medip Academy. This is an open-access article distributed under \\ the terms of the Creative Commons Attribution Non-Commercial License, which permits unrestricted non-commercial \\ use, distribution, and reproduction in any medium, provided the original work is properly cited.
}

\begin{abstract}
Background: The incidences of thyroid malignancies are rising across many parts of the world, due to various reasons. Among all the thyroid malignancy, Papillary Carcinoma of Thyroid (PTC) is the most common type, but fortunately if follows a slow course with excellent survival statistics. Papillary Thyroid Cancer has varied presentations and it has been observed that PTC is commonly found in association with Lymphocytic thyroiditis. In this study, we aim to analyse the mode of presentation of PTC, along with the diagnostic modalities and its relationship with Lymphocytic thyroiditis.

Methods: A total of 80 patients who were operated at a tertiary care hospital in south Kerala and had a histopathological diagnosis of Papillary Carcinoma of thyroid were included in the study. The presenting complaints, clinical signs, pre-operative thyroid function tests, ultrasonography findings, FNAC reports and pathology reports were obtained from the patient records.

Results: Mean ages of the participants were 44.6 years and vast majorities (80\%) were females. All the participants had a neck swelling at the time of presentation while $6.2 \%$ of the participants presented with hyperthyroid/thyrotoxicosis symptoms and $23.1 \%$ had symptoms suggestive of hypothyroidism. Fifty percent of the participants had an associated lymphocytic thyroiditis.

Conclusions: The mode of initial clinical presentation of this malignancy is varied and can range from hypothyroidism to thyrotoxicosis to a neck swelling. Biochemically also, we have found that the Thyroid Function Tests can yield a result in any part of the wide spectrum between hypothyroidism and hyperthyroidism. Also, it was found that no clinical or a laboratory finding was associated with the presence of lymphocytic thyroiditis in patients with Papillary Carcinoma of thyroid.
\end{abstract}

Keywords: Papillary carcinoma of thyroid, Lymphocytic thyroiditis, Total thyroidectomy, Histopathology

\section{INTRODUCTION}

Thyroid cancers are becoming a leading cause of morbidity in many parts of the world. This is especially true in the state of Kerala, India where up to $8.1 \%$ of all malignancies among females are thyroid cancers. It is startling that cancer registry statistics show an increase in relative proportion of thyroid malignancies from $6.5 \%$ to $8.1 \%$ in a short span of 5 years. ${ }^{1}$ The thyroid cancers vary in their presentation, clinical course and prognosis. The treatments of thyroid cancers also differ widely according to their histopathological type and grade. Follicular and Papillary thyroid cancers are the most frequent and curable of all thyroid malignancies. $^{2}$

Papillary thyroid cancer (PTC) itself has multiple variants, with varied clinical course and survival parameters. Conventional, Follicular, Tall Cell and 
Oncocytic variants are the most common ones found in India, with the Tall Cell variant indicating a poorer prognosis. ${ }^{3}$ Multiple studies have documented the excellent prognosis that is generally observed in patients with papillary carcinoma thyroid. Only less than $10 \%$ of the patients with papillary carcinoma of thyroid presents with secondary nodal involvement or distant metastasis. ${ }^{4}$ The cancer is also found to have a relatively slow course and this significantly affects the prognosis, albeit in a positive way. Another unique feature of this cancer is that occult papillary carcinoma of thyroid is frequent and gets diagnosed in people who are undergoing thyroid surgery for benign causes. Certain studies have found a prevalence rate of up to $10 \%$, of occult papillary cancer in patients undergoing thyroid surgery for other causes. Some studies estimate that the prevalence of occult thyroid cancers are in the range of $5-10 \%$, but only $1-2 \%$ of them may evolve into overt tumors during the lifetime of the patient. ${ }^{5}$

The association of papillary carcinoma of thyroid and chronic lymphocytic thyroiditis is well documented in studies. Studies indicate that the presence of chronic lymphocytic thyroiditis correlates well with a lower grade of papillary carcinoma, but no changes in overall survival could be demonstrated. Also, it is found that the association of papillary carcinoma and chronic lymphocytic thyroiditis is stronger in females than in males. ${ }^{6}$

Papillary thyroid cancers are predominantly found in women and the mean age of presentation tends to be below 45 years. The clinical characteristics of papillary carcinoma of thyroid are varied. The patients can present with symptoms and signs of hypothyroidism, hyperthyroidism or even in a euthyroid state. A good number of patients presents with history of a slow growing swelling in the front of their neck. Up to $25 \%$ of the patients tend to have multifocal disease at the time of presentation. ${ }^{7}$ The diagnostic modalities for papillary thyroid cancers are similar to other thyroid malignanciesultrasonic imaging of the neck, fine needle aspiration cytology and physical examination. This is followed by surgical management, with Iodine-131 therapy and lifelong TSH suppressive thyroid hormone replacement. ${ }^{8}$ There is a long running debate on the surgical method of choice in papillary carcinoma of thyroid, in view of its long natural history and relatively favourable prognosis. Though a section of surgeons prefer partial resection of the gland, many studies have conclusively proven the benefits of doing a total thyroidectomy. A total thyroidectomy addresses the chance of a multifocal tumour and helps in post-operative monitoring through radio-iodine scintigraphy and thyroglobulin level monitoring. 9

Papillary thyroid micro-carcinoma (PTMC) is a clinical and pathologically distinct entity. It is defined as a papillary thyroid cancer with the largest diameter measuring less than $10 \mathrm{~mm}$. It is the most common form of any malignancy and has been found in up to $36 \%$ of autopsy studies. It is often multifocal and the diagnosis is mostly incidental- in those patients who undergoes thyroidectomy for benign causes. ${ }^{10}$ Even though there is a huge debate on the preferred treatment modality in papillary thyroid micro-carcinoma, the current recommendations are similar to the treatment offered to patients with well differentiated papillary carcinoma of thyroid. $^{11}$

In this study we attempt to find out the clinical characteristics at presentation, diagnostic modalities used and pre-operative diagnosis, among patients diagnosed to have papillary carcinoma of thyroid pre-operatively or post-operatively. Only those patients undergoing thyroidectomy for any cause, with a cytology or histopathology report showing the presence of papillary carcinoma thyroid, were included in the study. Also we have attempted to objectively analyse the relationship between papillary carcinoma of thyroid and lymphocytic thyroiditis.

\section{METHODS}

This was a retrospective study using data from patients undergoing thyroidectomy over a period of 3 years- from January 2012 to December 2014. A total of 80 patients who had papillary carcinoma thyroid and underwent thyroidectomy at a tertiary care teaching hospital in Kerala state of India, were selected for the study. Participants, who had apre-operative fine needle aspiration cytology (FNAC) report suggestive of papillary carcinoma thyroid or a post-operative histopathology report of papillary thyroid cancer, were included in the study.

Potential participants were identified using data archived in the department of Pathology of the institution. All those patients who underwent surgery during the above mentioned period and had a valid FNAC or histopathology report of papillary thyroid cancer were selected as potential participants. The Medical Records department was contacted and the patient records of these potential participants were reviewed. Those with missing patient records or those patients who did not undergo a thyroidectomy at our centre after undergoing an FNAC here, were excluded from the study.

Data on presenting complaints, clinical signs, preoperative thyroid function tests, ultrasonography findings, FNAC reports and histopathological findings were obtained from the patient records. The obtained data was entered into a database management system using Microsoft Access and statistical analysis was done using SPSS 20.0.

\section{RESULTS}

There were 80 patients who satisfied the inclusion and exclusion criteria, over a period of 3 years. The mean 
(SD) age of the participants were 44.6 years (13.2 years), with the age ranging from 19 years to 90 years. A vast majority of those who underwent thyroidectomy and diagnosed as papillary carcinoma thyroid, were females. Sixty four $(80 \%)$ of the participants were females while $16(20 \%)$ were males.

The review of patient data revealed varied presenting complaints. Five $(6.2 \%)$ of the participants presented with hyperthyroid/thyrotoxicosis symptoms while 18 $(23.1 \%)$ had symptoms suggestive of hypothyroidism. All the patients who were included in the study had history of neck swelling. Thirty five $(43.8 \%)$ of the participants had compressive symptoms like dysphagia and 17 (21.3\%) complained of hoarseness of voice or change in voice (Table 1).

Table 1: Symptoms and signs on initial presentation to general surgery department.

\begin{tabular}{|lll|}
\hline $\begin{array}{l}\text { Symptoms/signs on initial } \\
\text { presentation }\end{array}$ & Number & Percentage \\
\hline $\begin{array}{l}\text { Hyperthyroid symptoms } \\
\text { Yes }\end{array}$ & 5 & 6.2 \\
No & 75 & 93.8 \\
\hline Hypothyroid symptoms & & \\
Yes & 18 & 23.1 \\
No & 60 & 76.9 \\
\hline Neck Swelling & & \\
Yes & 80 & 100 \\
No & 0 & 0 \\
\hline Compressive symptoms & & \\
Yes & 35 & 43.8 \\
No & 45 & 56.2 \\
\hline Hoarseness of voice & & \\
Yes & 17 & 21.3 \\
No & 63 & 78.7 \\
\hline
\end{tabular}

The institutional protocol asks for a clinically and biochemically euthyroid state before patients undergo thyroidectomy, unless there is a foreseeable emergency. The pre-operative Thyroid Stimulating Hormone (TSH) values are indicative of this protocol and is in the range of 0.1 to 5 with a mean (SD) of $1.79 \mathrm{mU} / \mathrm{L}(1.02 \mathrm{mU} / \mathrm{L})$. The pre-operative neck ultrasonography had stated that $51(63.8 \%)$ participants had Solitary Nodule of Thyroid, while $26(32.5 \%)$ had multinodular goitre. Only $3(3.8 \%)$ of the patients had ultrasonography report suggestive of diffuse goitre.

The Fine Needle Aspiration cytology (FNAC) done preoperatively revealed that $16(20 \%)$ of the patients had papillary thyroid cancer, $36(45 \%)$ had a follicular neoplasm and $28(35 \%)$ as having colloid goitre. But the histopathology report on the post-operative specimen showed that all the 80 participants had papillary thyroid cancer, with $40(50 \%)$ having an associated Lymphocytic thyroiditis (Table 2).
Table 2: Result of investigations.

\begin{tabular}{|lll|}
\hline Result of investigations & Number & Percentage \\
\hline $\begin{array}{l}\text { Neck Ultrasonography } \\
\text { Solitary nodule thyroid }\end{array}$ & 51 & 63.8 \\
$\begin{array}{l}\text { Multinodular goitre } \\
\text { Diffuse goitre }\end{array}$ & 26 & 32.5 \\
\hline $\begin{array}{l}\text { Fine needle aspiration } \\
\text { cytology }\end{array}$ & 3 & 3.8 \\
$\begin{array}{l}\text { Papillary thyroid } \\
\text { carcinoma }\end{array}$ & 16 & 20.0 \\
$\begin{array}{l}\text { Follicular neoplasm } \\
\text { Colloid goitre }\end{array}$ & 36 & 45.0 \\
\hline $\begin{array}{l}\text { Histopathology of specimen } \\
\text { Papillary thyroid cancer } \\
\text { (PTC) only }\end{array}$ & 28 & 35.0 \\
$\begin{array}{l}\text { PTC along with } \\
\text { lymphocytic thyroiditis }\end{array}$ & 40 & 50.0 \\
\hline
\end{tabular}

All the patients underwent a near total, total or completion thyroidectomy at Pushpagiri Medical College Hospital, a tertiary care teaching hospital in the state of Kerala, India. The mean (SD) length of the post-operative specimen was $4.81 \mathrm{~cm}(0.96 \mathrm{~cm})$ with a minimum of $3 \mathrm{~cm}$ and a maximum of $6 \mathrm{~cm}$. The mean (SD) breadth of the specimen was $4.25 \mathrm{~cm}(1.28 \mathrm{~cm})$ with the minimum breadth being $2 \mathrm{~cm}$ and the maximum being $7 \mathrm{~cm}$.

The data was further analysed to look for factors associated with lymphocytic thyroiditis in patients with papillary carcinoma of thyroid. Sixty two percent of the males had associated lymphocytic thyroiditis while only $46.9 \%$ of the females had it, with an Odds Ratio $(95 \%$ CI) of 1.88 (0.61 to 5.81). Forty percent of the participants with hyperthyroid symptoms and $50.7 \%$ with no hyperthyroid symptoms had lymphocytic thyroiditis associated with papillary thyroid cancer, but the difference was not found to be statistically significant (p1.000). Hypothyroid symptoms were also not significantly associated presence of Lymphocytic thyroiditis with $44.4 \%$ of participants with hypothyroid symptoms and $51.7 \%$ of people with no hypothyroid symptoms, having Lymphocytic thyroiditis (p- 0.789). Fifty one percent of the participants with compressive neck symptoms had associated lymphocytic thyroiditis while $48.9 \%$ without any compressive symptoms had the same, with an Odds ratio (95\% CI) of 1.10 (0.45 to 2.67). Forty two percent of the participants with hoarseness of voice and $52 \%$ without hoarseness had lymphocytic thyroiditis and the difference was not statistically significant on test of proportions (p- 0.586). Ultrasound findings (p- 0.838) and FNAC reports (p-0.343) were also not associated with the presence of lymphocytic thyroiditis in patients with papillary thyroid cancer.

The mean (SD) age of those participants having associated Lymphocytic thyroiditis was 43.9 years (10.8 years) and that of participants with papillary carcinoma of thyroid only was 45.4 years (15.4 years), and this difference was not significant on test of means ( $p-0.599)$. 
Also there was no statistically significant difference in the length (p- 0.909$)$ or breadth $(0.731)$ of the specimens between participants with associated lymphocytic thyroiditis and with papillary thyroid cancer alone.

Table 3: Characteristics predicting associated lymphocytic thyroiditis among patients with Papillary Thyroid Carcinoma (PTC).

\begin{tabular}{|c|c|c|c|c|}
\hline Characteristic & $\begin{array}{l}\text { Papillary carcinoma thyroid } \\
\text { + lymphocytic thyroiditis }\end{array}$ & $\begin{array}{l}\text { Papillary carcinoma } \\
\text { thyroid alone }\end{array}$ & P value & $\begin{array}{l}\text { Odds Ratio }(95 \% \\
\text { CI) }\end{array}$ \\
\hline \multicolumn{5}{|l|}{ Sex } \\
\hline Male & $10(62.5 \%)$ & $6(37.5 \%)$ & \multirow{2}{*}{0.402} & \multirow{2}{*}{1.88 (0.61 to 5.81$)$} \\
\hline Female & $30(46.9 \%)$ & $34(53.1 \%)$ & & \\
\hline \multicolumn{5}{|c|}{ Hyperthyroid symptoms } \\
\hline Yes & $2(40 \%)$ & $3(60 \%)$ & \multirow{2}{*}{0.999} & \multirow{2}{*}{$0.64(0.10$ to 4.11$)$} \\
\hline No & $38(50.7 \%)$ & $37(49.3 \%)$ & & \\
\hline \multicolumn{5}{|c|}{ Hypothyroid symptoms } \\
\hline Yes & $8(44.4 \%)$ & $10(55.6 \%)$ & \multirow{2}{*}{0.789} & \multirow{2}{*}{0.74 (0.26 to 2.15$)$} \\
\hline No & $31(51.7 \%)$ & $29(48.3 \%)$ & & \\
\hline \multicolumn{5}{|l|}{ Swelling } \\
\hline Yes & $40(50 \%)$ & $40(50 \%)$ & \multirow{2}{*}{-} & \multirow[b]{2}{*}{ - } \\
\hline No & 0 & 0 & & \\
\hline \multicolumn{5}{|c|}{ Compressive symptoms } \\
\hline Yes & $18(51.4 \%)$ & $17(48.6 \%)$ & \multirow{2}{*}{0.999} & \multirow{2}{*}{$1.10(0.45$ to 2.67$)$} \\
\hline No & $22(48.9 \%)$ & $23(51.1 \%)$ & & \\
\hline \multicolumn{5}{|l|}{ Hoarseness of voice } \\
\hline Yes & $7(42.1 \%)$ & $10(58.8 \%)$ & \multirow{2}{*}{0.586} & \multirow{2}{*}{$0.63(0.21$ to 1.88$)$} \\
\hline No & $33(52.4 \%)$ & $30(47.6 \%)$ & & \\
\hline \multicolumn{5}{|l|}{ Ultrasound findings } \\
\hline Solitary nodule & $25(49 \%)$ & $26(51 \%)$ & \multirow{3}{*}{0.838} & \multirow{3}{*}{-} \\
\hline Multinodular goitre & $13(50 \%)$ & $13(50 \%)$ & & \\
\hline Diffuse goitre & $2(66.7 \%)$ & $1(33.7 \%)$ & & \\
\hline \multicolumn{5}{|l|}{ FNAC findings } \\
\hline Papillary carcinoma & $6(37.5 \%)$ & $10(62.5 \%)$ & \multirow{3}{*}{0.343} & \multirow{3}{*}{-} \\
\hline Follicular neoplasm & $21(58.3 \%)$ & $15(41.7 \%)$ & & \\
\hline Colloid goitre & $13(46.4 \%)$ & $15(53.6 \%)$ & & \\
\hline
\end{tabular}

\section{DISCUSSION}

Cholelithiasis is the most common biliary pathology. Gall As found out in multiple studies done across the world, the mean age of presentation of papillary carcinoma of thyroid is below 45 years and a vast majority of the patients are females. ${ }^{1,7}$ The mode of initial clinical presentation of this malignancy is varied and can range from hypothyroidism to thyrotoxicosis to a neck swelling. Biochemically also, we have found that the Thyroid Function Tests can yield a result in any part of the wide spectrum between hypothyroidism and hyperthyroidism. This is similar to previously reported studies from other centres. $^{7}$

The unique association of papillary carcinoma of thyroid with lymphocytic thyroiditis is demonstrated in our study also. A large number of previous studies have reported this association and its clinical significance. ${ }^{6}$ In our study, $50 \%$ of all participants with papillary thyroid cancer had an associated lymphocytic thyroiditis. On further analysis to find out whether we can use the clinical features or pre-operative investigations to predict the presence of lymphocytic thyroiditis in patients with papillary thyroid cancer, it was found that none of these characteristics were associated with the presence of lymphocytic thyroiditis. Also, there were no differences in sex, age or even size of the tumour, between those participants with lymphocytic thyroiditis and those without the same. Certain studies have suggested that Lymphocytic thyroiditis is a precursor of papillary thyroid cancer, but this possibility has not been evaluated in our study due to the limitations of a cross sectional design. ${ }^{12}$

In our study, it was found that almost $80 \%$ of the patients underwent thyroidectomy for reasons other than papillary carcinoma of thyroid. This point towards the inherent limitations of the traditional methods of diagnosing thyroid cancers. ${ }^{8}$ Thus, along with the varied clinical presentation, demonstrates the necessity of suspecting and evaluating for papillary thyroid cancer in any patient presenting with a swelling of the neck. 


\section{CONCLUSION}

The possible causal association between Lymphocytic thyroiditis and thyroid malignancy needs to be further evaluated. Larger and more extensive studies with a longitudinal study design can help us in finding out the temporal association and analyse the causal element. This can go a long way in preventing the morbidity and mortality due to papillary carcinoma of thyroid.

\section{ACKNOWLEDGEMENTS}

The authors would like to thank the patients, students, management and faculty members of Pushpagiri Medical College Hospital, Tiruvalla, Kerala, India.

Funding: No funding sources

Conflict of interest: None declared

Ethical approval: The study was approved by the institutional ethics committee

\section{REFERENCES}

1. Individual registry- leading site graphs. (Last accessed on 2015 Dec 28) Available from: http://www.ncrpindia.org/all_ncrp_reports/trend_rep ort_1982_2010/all_content/all_pdf/individual_regist ry_leading_site_graphs.pdf.

2. Schlumberger MJ, Torlantano M. Papillary and follicular thyroid carcinoma. Baillieres Best Pract Res ClinEndocrinolMetab. 2000;14(4):601-13.

3. Ito $\mathrm{Y}$, Hirokawa $\mathrm{M}$, Uruno $\mathrm{T}$, Kihara $\mathrm{M}$, Higashiyama T, Takamura Y, et al. Prevalence and biological behaviour of variants of papillary thyroid carcinoma: experience at a single institute. Pathology. 2008;40(6):617-22.

4. Dorairajan N, Pandiarajan R, Yuvaraja S. A descriptive study of papillary thyroid carcinoma in a teaching hospital in Chennai, India. Asian J Surg. 2002;25(4):300-3.

5. Pelizzo MR, Piotto A, Rubello D, Casara D, Fassina A, Busnardo B. High prevalence of occult papillary thyroid carcinoma in a surgical series for benign thyroid disease. Tumori. 1990;76(3):255-7.

6. De Manzini N. Coexistence of ChronicLymphocytic Thyroiditis and Papillary Thyroid carcinoma. Impact on presentation, management, and outcome. Int J Surg. 2015;S1743-9191(15)01449-1.

7. Huang G, Tian X, Li Y, Ji F. Clinical characteristics and surgical resection of multifocal papillary thyroid carcinoma: 168 cases. Int J ClinExp Med. 2014;7(12):5802-7.

8. Pelizzo MR, Boschin MI, Toniato A, Pagetta C, Casal Ide E, Mian C, Rubello D. Diagnosis, treatment, prognostic factors and long-term outcome in papillary thyroid carcinoma. Minerva Endocrinol. 2008;33(4):359-79.

9. Sosa JA, Udelsman R. Total thyroidectomy for differentiated thyroid cancer. J SurgOncol. 2006;15;94(8):701-7.

10. Sakorafas GH, Giotakis J, Stafyla V. Papillary thyroid microcarcinoma: a surgical perspective. Cancer Treat Rev. 2005;31(6):423-38.

11. Küçük NO, Tari P, Tokmak E, Aras G. Treatment for microcarcinoma of the thyroid--clinical experience. ClinNucl Med. 2007;32(4):279-81.

12. Okayasu I, Fujiwara M, Hara Y, Tanaka Y, Rose NR. Association of chronic lymphocytic thyroiditis and thyroid papillary carcinoma. A study of surgical cases among Japanese, and white and African Americans. Cancer. 1995;76(11):2312-8.

Cite this article as: Gopal MV, Hassan $\mathrm{N}$, Thomas AS, Thomas PT. Association of lymphocytic thyroiditis and papillary thyroid carcinoma: a retrospective study done at a tertiary care centre in Kerala, India. Int Surg J 2016;3:68791. 